\title{
Fannia carvalhoi sp. nov.: a new species from Peru (Diptera, Fanniidae)
}

\author{
Márcia S. Couri ${ }^{1,2}$ \\ ${ }^{1}$ Departamento de Entomologia, Museu Nacional, Quinta da Boa Vista, 20940-040, Rio de Janeiro-RJ, BRASIL. mcouri@attglobal.net \\ ${ }^{2}$ Fellowship of Conselho Nacional de Desenvolvimento Científico e Tecnológico, CNPq
}

\begin{abstract}
Fannia carvalhoi sp. nov.: a new species from Peru (Diptera, Fanniidae). Fannia carvalhoi sp. nov. (Diptera, Fanniidae) from Peru is described and illustrated.
\end{abstract}

KEYWORDS. Fanniidae, F. carvalhoi, morphology, taxonomy.

RESUMO. Fannia carvalhoi sp. nov.: uma nova espécie do Peru (Diptera, Fanniidae). Fannia carvalhoi sp. nov. (Diptera, Fanniidae) do Peru é descrita e ilustrada.

PALAVRAS-CHAVE. Fanniidae, F. carvalhoi, morfologia, taxonomia.

The most recent catalogue of the Neotropical Fanniidae lists 63 species of Fannia Robineau- Desvoidy, 1830 to this region (Carvalho et al., 2003), 13 of which are recorded from Peru. More recently, three other Neotropical species were described (Couri, 2004 and Couri \& Winagraski, 2005).

In this study a new species of Fannia is described and illustrated. The material was collected in Peru and all the typematerial is deposited at Museu Nacional, Rio de Janeiro (Brazil) collection (MNRJ).

The terminalia were prepared in solution of potassium hydroxide at $10 \%$, in water-bath, for ten minutes. They were then dissected in glycerol, drawn and packed in microtube with glycerol and fixed to the pin together with the specimen.

\section{Fannia carvalhoi sp. nov.}

(Figs 1-12)

Colour. Brown with grey pollinosity. Head with frons, face, fronto-orbital plate and gena brown; antenna brown, flagellum with a faint pollinosity; palpus brown. Mesonotum brown. Calypters yellowish white; halter yellow; wing hyaline. Legs brown; pulvillus white; claws black. Abdomen brown with yellow lateral marks on tergites 3 and 4 in males (Fig. 1).; females also with the tergite 1+2 yellow on basal half(Fig. 2).

Length. Male: body: 4.0-4.2 mm; wing: 4.2-4.4 mm

Head. Eye bare, anterointernal facets larger; holoptic, interocular space at vertex as wide as ocellar triangle. Thirteen to fourteen pairs of long frontal setae. Inner and outer vertical setae delicate. Ocellar seta short. Antenna inserted below middle of eyes; flagellum about 1.8-2.0 as long as pedicel. Arista shortly pubescent. Vibrissa short.

Thorax. Acrostichal setulae in 3-4 desarranged rows, prescutellar pair developed; dorsocentrals 2:3; 2 humerals, one strong and the other medium developed; 1 posthumeral; 1 presutural and 2 postsutural intra-alars; 2 supra-alars.
Scutellum with one sub-basal and one apical pair of setae, both long. Notopleuron with two long and similar setae. Anepisternum with a row of about 5 strong setae and others finer ones. Lower calypter about 1.6 times the upper one. Fore femur with a complete posterodorsal row of setae, posteroventral surface with a row of scattered setae. Fore tibia with one preapical dorsal seta and 2 apical ventral very short. Mid femur with an anteroventral and a posteroventral row of setae, longer and stronger on apical third. Mid tibia swallowed on basal third; one strong apical ventral seta (Fig. 3). Hind femur enlarged preapically in a distinct swelling, with a tuft of setae on its anteroventral and posteroventral surfaces (Fig. 4), apical dorsal third with a row of setae. Hind tibia with 1 submedian anterodorsal seta, 1 median posterodorsal long, and another dorsal on apical third; ventral surface with a very long and very strong curved seta which almost reaches the apex of pre-tarsus (Fig. 4).

Abdomen. Tergite 5 "U" shaped, with setae on ventral surface of the arms, longer at apex (Fig. 5).

Terminalia. Cercal plate short, with many setae on disk and two long ones on apical margin (Fig. 8); surstyli very long and fine; bacilliform process very long (Figs. 6-7). Aedeagus as in Fig. 9.

Female. Length. body: 4.0-4.3 mm; wing: $4.4 \mathrm{~mm}$

Similar to male differing as follows. Distance of the eyes about one third of the head width at vertex; hind femur with no swallowed area and no tuft of setae; hind tibia with a median anterodorsal and a posterodorsal setae, both inserted at the same level, one preapical posterodorsal and one apical ventral, not differentiated from the others as in male.

Terminalia. Ovipositor with large tergites and sternites, except sternite 8 which is reduced to two small plates, each one with 2 setae; intersegmentar membranae with spicules on both sides; 2 spermathecae round (Figs 10-12).

Discussion. The male of $F$. carvalhoi is easily recognized 


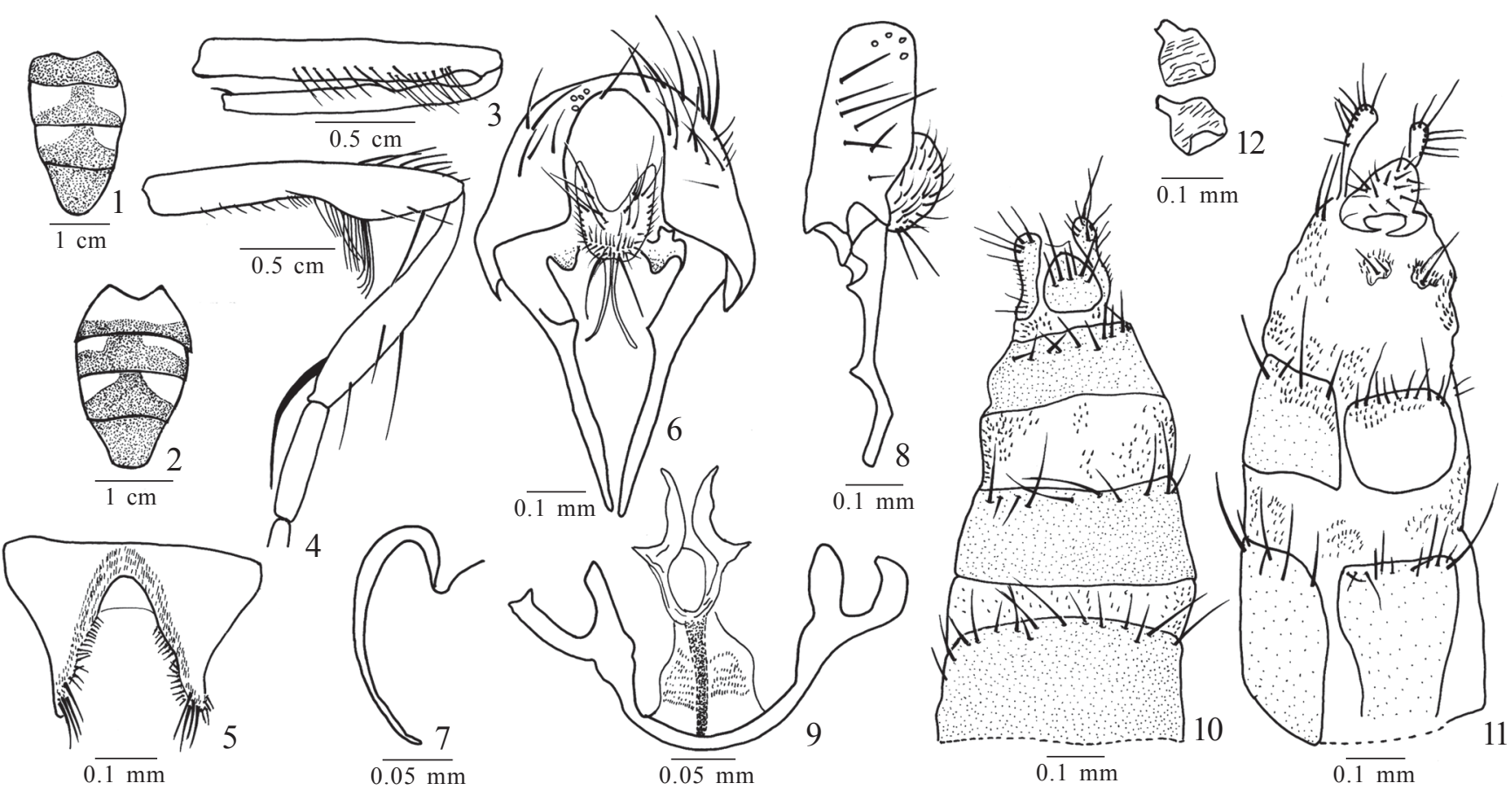

Figs. 1-12: Fannia carvalhoi sp. nov. 1, Male abdomen (holotype), dorsal view; 2, Female abdomen; 3, Male mid femur and tibia (holotype), anterior view; 4, Male hind femur and tibia (holotype), anterior view; 5, Sternite 5, holotype; 6, Cercal plate and surstyli, dorsal view, holotype; 7, Bacilliform process, holotype; 8, Cercal plate and surstyli, lateral view, holotype; 9, Aedeagal complex, holotype, lateral view; 10, Ovipositor, dorsal view; 11, Ovipositor, ventral view; 12, Spermathecae.

from their congeneres by the strong ventral preapical seta on hind tibia.

Etymology. The specific epithet is in homage to Dr. Claudio José Barros de Carvalho (Universidade Federal do Paraná, Brazil) for his contribution to the dipterology in the last decades and in gratitude to his long and healthy friendship.

Material examined: Holotype male: PERU: Junin Prov., $15 \mathrm{Km}$. W. San Rason, 1433m, asynanthropic, 5.vii.1980, M. Sayaka \& B. Greenberg col. Paratypes: same data as holotype: 1 male; same locality as holotype: 1 male: $23 \mathrm{Km} \mathrm{W.} \mathrm{San} \mathrm{Rason,} 1869 \mathrm{~m}$, asynanthropic, 1.vii.1980, M. Sayaka \& B. Greenberg col.; 2 females: 20 Km. W. San Rason, 30.vi.1980, M. Sayaka \& B. Greenberg col.; 1 female: $18 \mathrm{Km}$. W. San Rason, hemisynanthropic, 5.vii.1980, M. Sayaka \& B. Greenberg col.
Acknowledgments. The author is grateful to $\mathrm{CNPq}$ for her research grant (process number 300370/2004-0) and financial support to the project.

\section{REFERENCES}

Carvalho, C. J. B. de; A. C. Pont; M. S. Couri \& D. M. Pamplona. 2003. A catalogue of the Fanniidae (Diptera) of the Neotropical Region. Zootaxa 219: 1-32.

Couri, M. S. 2004.Two new species of Fannia Robineau-Desvoidy (Diptera, Fanniidae). Brazilian Journal of Biology 64: 767770.

Couri, M. S. \& E. Winagraski. 2005. A new Fannia (Diptera, Fanniidae) from Amazonas, Brazil, and new geographical record. Revista Brasileira de Zoologia 22: 645-647. 